\title{
ISTEC and MRS Cosponsor the 1995 International Workshop on Superconductivity
}

The International Superconductivity Technology Center (ISTEC) and the Materials Research Society (MRS) will hold their second joint international workshop on June 18-21, 1995, in Maui, Hawaii.

The theme of this year's Workshop will be "Controlled Processing of HighTemperature Superconductors: Fundamentals and Applications." The potential application and use of HTS in electrical and electronic devices will be included. The Workshop will be a single-session meeting, with a significant amount of time allotted to encourage exchange of information among the participants.

The topics will include:

- Thin Film Growth: process parameters, materials, homo/heteroepitaxy, phase stability, and characterization;

- Bulk Crystal Production: controlled crystal growth, bulk single crystals, introduction of pinning centers, thermody- namics and chemistry, phase transitions, and applications;

- Wire and Tape Production: long wire/tape production, key parameters for high $J_{c}, I_{c}$, stress effects and AC losses, and applications;

- Thin Film Applications: junction formation, lithographic technology, surface quality control, and applications;

- New Technology: innovative technology, new technology, processing for new materials and processes.

The chairs of the Workshop, S. Tanaka, (ISTEC) and J.M. Phillips (AT\&T Bell Labs) will present special lectures. $C-W$. (Paul) Chu (the Texas Center for Superconductivity at the University of Houston [TCSUH]), H. Hayakawa (Nagoya University), D.C. Larbalestier (University of Wisconsin), and Y. Tanaka (Furukawa Electric) have been invited to present talks at the plenary session.
The deadline for submissions of contributed abstracts has passed; however, late news papers will be considered subject to their appropriateness and available space. Extended Abstracts will be published and distributed to all participants at the Workshop. For further information about the Workshop, contact Tetsuji Kobayashi, Manager, International Affairs Department, International Superconductivity Technology Center (ISTEC), Eishin Kaihatsu Bldg., 6F, 34-3, Shimbashi 5-chome, Minatoku, Tokyo 105, Japan; telephone 81-3-34314002; fax 81-3-3431-4044.

Additional support is provided by The Japan Keirin Association; Argonne, Los Alamos, and Oak Ridge National Laboratories; TCSUH; the National High Magnetic Field Laboratory (Florida State University); and S \& T Center for Superconductivity (University of Illinois). The Workshop is endorsed by the Research and Development Association for Future Electron Devices, Materials Research Society of Japan, and the European Materials Research Society.

\section{Nuclear Waste Management Symposium Held in Japan}

The 18th International Symposium on the "Scientific Basis for Nuclear Waste Management" was held in Kyoto, Japan, from October 23-27, 1994. This symposium, normally held during the MRS Fall Meeting in Boston, rotates to other countries every third year. In previous years, it has been held in Berlin (1982, 1988), Stockholm (1985), and Strasbourg (1991). This was the first year that this symposium was held in an Asian venue.

Over 350 attendees from 19 nations participated in the presentation of over 180 posters and lectures. The symposium was sponsored by the Materials Research Society, the Atomic Energy Society of Japan, the Central Research Institute of Electric Power Industry, the Japan Atomic Energy Research Institute (JAERI), and the Power Reactor and Nuclear Fuel Development Corporation (PNC). The International Union of Materials Research Societies and MRS-Japan were two of ten cooperating societies. The overall chair of the meeting was Keiji Naito, a commissioner of the Nuclear Safety Commission. Kunio Higashi of Kyoto University chaired the organizing Committee; and Muneaki Senoo of JAERI served as the secretariat. Takashi Murakami (Ehime University) and Rod Ewing (University of New Mexico) chaired the Program Committee and will be the editors of the proceedings volume.

The meeting opened with a presentation by Masayoshi Hayashi of the Japan Atomic Energy Commission entitled, "The Role of Peaceful Use of Nuclear Energy" and an invited lecture by Ivars Neretnieks of the Royal Institute of Technology in Stockholm on "Nuclear Waste Repositories in Crystalline Rock: An Overview of Flow and Nuclide Transport Mechanisms in the Geologic Barrier." The meeting covered topics ranging from the materials science of waste forms (glass, crystalline ceramics, spent nuclear fuel, and concrete) to canister and backfill/buffer materials.

Beyond the materials science issues, scientists and engineers presented papers on radiation effects; radionuclide speciation, solubility and retardation; colloids; groundwater flow and transport process- es; performance and safety assessments; site characterization; processing and separation technologies; and the use of natural systems to model long-term processes. Invited speakers included Peter C. Lichtner of the Center for Nuclear Waste Regulatory Analyses in San Antonio, who spoke on the "Principles and Practice of Reactive Transport Modeling," and John C. Westall of Oregon State University, who spoke on the "Modeling of Metal Speciation in the Environment: Association of Metals with Heterogeneous Environmental Sorbents." The proceedings volume will have nearly 170 papers and be published by MRS as part of its continuing series for this symposium.

The meeting was followed by a number of technical tours which included the Tono Uranium Mine research center operated by PNC and the research facilities of JAERI and PNC in Tokai.

Considerable efforts were made to provide funds in support of foreign participants, particularly young scientists; this insured a strong foreign attendance.

The next meeting of this symposium to be held outside of the United States will be in Switzerland in October of 1997. 